Yüzüncü Y1l Üniversitesi
Tarim Bilimleri Dergisi

Araştırma Makalesi (Research Article)

\title{
Ekmeklik Buğdayda Optik Sensör ile Azotlu Gübre Tavsiyesi
}

\section{Erdinç SAVAŞLI ${ }^{* 1}$, Oğuz ÖNDER ${ }^{2}$, Ramis DAYIOĞLU ${ }^{3}$, Didem ÖZEN ${ }^{4}$, Yaşar KARADUMAN $^{5}$, Suat ÖZDEMİR ${ }^{6}$, Özgür ATEŞ ${ }^{7}$, Melih ÖZSAYIN ${ }^{8}$}

\author{
1,2,3,4,6,7,8 Transitional Zone Agricultural Research Institute, Eskișehir, Turkey \\ ${ }^{5}$ Department of Food Engineering, Osmangazi University, Eskişehir, Turkey \\ ${ }^{1}$ https://orcid.org/0000-0001-5326-4710 ${ }^{2}$ https://orcid.org/0000-0002-8184-1316 ${ }^{3}$ https://orcid.org/0000-0002-7134-4965 \\ ${ }^{4}$ https://orcid.org/0000-0002-2495-0516 ${ }^{5}$ https://orcid.org/0000-0002-5089-807X ${ }^{6}$ https://orcid.org/0000-0003-1306-3572 \\ ${ }^{7}$ https://orcid.org/0000-0002-9345-417X ${ }^{8}$ https://orcid.org/0000-0002-0332-0734 \\ *Sorumlu yazar e-posta: esavasli26@gmail.com
}

\section{Makale Bilgileri}

Geliş: 23.04.2020

Kabul: 22.02.2021

Online Yayınlanma 30.06.2021

DOI: 10.29133/yyutbd.726039

\section{Anahtar kelimeler}

Azot,

Buğday,

NDVI,

Optik sensör.
Öz: $\mathrm{Bu}$ çalışma, Eskişehir Geçit Kuşağı Tarımsal Araştırma Enstitüsü arazisinde 2017-2019 yılları arasında yürütülmüştür. Çalışmada, Hat 30, Mesut, Nacibey ve Reis kışlık ekmeklik buğday çeşitlerinin kuru koşullar altında azot gübrelemesine verdikleri tepkiler, spektral yansımaya dayalı bitki örtüsü indeksleri ve bu indekslerden hesaplanan Mevsimsel Verim Tahminleri ile karşılaştırılmıştır. Örtü indekslerinin ölçülmesinde Optik sensör (Green Seeker) kullanılmıştır. Denemede Tesadüf Bloklarında Faktöriyel Deneme Deseni ve 6 farklı $0,30,60,90,120$ ve $150 \mathrm{~kg} / \mathrm{ha}$ azot dozu kullanılmıştır. Vejetasyon indeksleri (NDVI) Zadoks24, Zadoks30, Zadoks31 ve Zadoks32 büyüme dönemlerinde okunmuştur. Zadoks30 (sapa kalkma dönemi) en gerçekçi okuma dönemi olarak bulunmuştur. 3 deneme ortalamasına göre yeni sistemin, ilkbahar (Zadoks30) dönemi uygulamalarında $15 \mathrm{~kg} / \mathrm{ha}$ daha az azot ile benzer verim değerleri sağladıği ve ümit verici olduğunu görülmüştür. Sensör uygulamasının çiftçi uygulamasından \% 5 daha etkin olduğu belirlenmiştir.

\section{Nitrogen Fertilizer Recommendation with Optical Sensor for Bread Wheat Varieties}

\section{Article Info}

Received: 23.04.2020

Accepted: 22.02.2021

Online Published 30.06.2021

DOI: 10.29133/yyutbd.726039

\section{Keywords}

Nitrogen,

Wheat,

NDVI,

Optic sensor.

\begin{abstract}
This study was conducted at Transitional Zone Agricultural Research Institute in Eskisehir, in 2017-2019 growing seasons. In the study, responses of four winter wheat cultivars (Hat30, Mesut, Nacibey and Reis) to nitrogen fertilization under rainfed conditions were compared with vegetation indices based on spectral reflection and In- Season Estimates of Yield calculated from these indices. Optical -held sensor (Green Seeker) was used for this purpose. The experimental layout were used 0, 30, 60, 90, 120 and $150 \mathrm{~kg} \mathrm{~N} / \mathrm{ha}$ nitrogen rates 2 factor factorial in randomized complete block design in the experiment. Vegetation indices (NDVI) were obtained at growth stages Zadoks24, Zadoks30, Zadoks31 and Zadoks32. Zadoks30 (stem elongation) was found to be the most realistic reading time. Based on the average of 3 experiment fields, the new system resulted in the similar yields with that of $15 \mathrm{~kg} / \mathrm{ha}$ less nitrogen in the spring (Zadoks30) season, promising to be input saving and profitable. The sensor application was found to be $5 \%$ more effective than that of farmer application.
\end{abstract}




\section{Giriş}

Son yıllarda farklı bitki türlerinde sensörler yardımıyla geliştirilen kalibrasyon denklemleriyle azotlu gübre tavsiye sistemleri kullanılmaya başlanmıştır (Franzen ve ark., 2016). En uygun azotlu gübre tavsiyeleri belirlenirken hedeflenen verim ve çiftçilerin geçmiş tecrübeleri önemli rol oynamaktadır(Westfall ve ark., 1996). Optik sensör ile aynı verim seviyelerinde daha az azot kullanılarak ekonomik bir girdi sağlarnırken aynı zamanda çevreye verilen zararda önemli ölçüde azaltılabilmektedir. Beklenen verimler iklimin durumuna göre, tarladan tarlaya ve yıldan y1la farkl111k gösterebilmektedir. Büyüme mevsimin başlarında gübre uygulamasından önce verimin ve azota tepkilerin tahmin edilmesi zordur. Bu nedenle azot (N) eksikliklerini tespit etmek ve mevsim içi gübre tavsiyelerini belirlemek amacıyla optik sensorlerin kullanımı artmıştır (Jacop ve ark., 2018). Bu amaçla INSEY (In-Season Estimated Yield = Mevsim İçi Verim Tahmini) değerleri ile verim arasındaki ilişkiyi gösteren kalibrasyon eğrileri oluşturulmakta ve daha sonra, çiftçi tarlalarında yapılacak tavsiyelerin hesaplanmasında bu denklemlerden yararlanılmaktadır. Her bölge için geliştirilen kalibrasyon denklemleri çiftçi tarlalarında oluşturulan zengin şeritler (azotça zenginleştirilmiş) ile test edilmelidir.

Klorofil, bitkilerin yeşil renginden sorumlu pigmenttir ve fotosentezdeki 1şı̆̆ yakalayan ve bitkide enerji üretimini belirleyen temel unsurdur (Araus ve ark., 1997). Optik sensorlerin kullanılmasında temel prensip buğdayda fazla veya yetersiz azotlu gübrelemede görülen yeşil renkteki klorofildeki değişimlere dayanmaktadır. Azot eksikliği, yaprak klorofil konsantrasyonlarında azalmaya neden olmakta (Peñuelas ve ark., 1993) ve Filella ve ark., 1995) yakın-kızılötesi yansımadaki azalmalarsa yaprak alan indeksi ve yeşil biyolojik kütledeki azalmaları göstermektedir (Jensen ve ark., 1990). Bitkilerin spektrumun kırmızı ve yakın-kızılötesi (near-infrared) bölgelerinde (farklı nanometre okumalarında) verdikleri yansıma değerleri karşılaştırılarak gelişme durumunu gösteren vejetasyon indeksleri elde etmeye dayanan optik sensörle azotlu gübre tavsiye sistemlerinde en yaygın olarak kullanılan Normalize Edilmiş Vejetasyon İndeks Farkı (NDVI) ve basit oran Simple Ratio (SR) olmaktadır (Aparicio ve ark., 2002). Yapılan çalışmalar kışlık buğdayda optik sensör yansımalarının toplam bitki kütlesi (biyomas) ile yüksek korelasyon verdiği (Stone ve ark., 1996), sapa kalkma başlangıcında sensör yansıma değerleri aracılığıyla verim potansiyelinin belirlenebileceğini göstermiştir (Raun ve ark., 2002). Savaşlı ve ark., tarafından 2018 yılında yürütülen optik sensor çalışmalarında da erken dönem (ekim+kardeşlenme dönemi) azot uygulamaların verim üzerine etkili olduğu bildirilmiştir. Bijay-Singh ve ark. (2013) ekimle ve iki kardeş döneminde azotlu gübre iki eşit dönemde $3 \mathrm{~kg}$ N/da olarak verildiğinde ve maksimum kardeşlenme dönemi öncesinde SPAD ve NDVI okumaları yapılarak elde edilen 0.005-0.011 INSEY değerleri arasında iken uygulanan azot ile maksimum verim artışı sağlandığı belirtilmiştir. Yürütülen başka çalışmalarda da klorofil konsantrasyonların belirlenmesinde SPAD-502 ve RGB görüntü işleme tekniklerin kullanılabileceği ifade edilmiştir (Odabaşı ve ark., 2015).

$\mathrm{Bu}$ çalışmada, son yıllarda kullanımı yaygınlaşan optik sensorler kullanılarak ekmeklik buğdayda kuru koşullar altında en yüksek tane verimini hedefleyen optimal azot tavsiyesi için geliştirilen kalibrasyon denklemleri ve elde edilen sonuçlar değerlendirilmiştir.

\section{Materyal ve Yöntem}

Denemede, kuru koşullar için son yıllarda geliştirilen Reis, Mesut, Nacibey çeşitleri ve ileri kademe ümitvar Hat30 kullanılmıştır. “Tesadüf Bloklarında Faktöriyel Deneme Deseni” nde yürütülen denemede 0, 3, 6, 9, 12 ve $15 \mathrm{~kg} \mathrm{~N} /$ da azot seviyeleri karşılaştırılmıştır. Kardeşlenme dönemi (Zadoks 24), sapa kalkma başlangıcı (Zadoks30), sapa kalkma 1. boğumlu dönem (Zadoks31) ve sapa kalkma 2 .boğumlu dönem (Zadoks32) olmak üzere 4 farklı dönemde vejetasyon indeksi (NDVI) okumaları yapılmıştır (Zadoks,1974). Oklahoma Eyalet Üniversitesi uyguladığı yöntem ile azotun tamamı ekimle birlikte verilmiştir (Raun ve ark., 2002). Bunun gerekçesi, azotlu gübrenin uygulanması sonrasında bitki tarafından alınıp klorofil oranları üzerinde etkisini göstermesi için gereken süre ortalama 4-5 hafta olarak ifade edilmektedir. Böylece kalibrasyonu oluşturacak azot dozlarının tamamını ekimle birlikte uygulayarak, NDVI okumalarında beklenen karşılıkların oluşmaması ihtimalini ortadan kaldırmaktır. Bu amaçla azotlu gübre dozlarının tamamı ekimle birlikte uygulanmıştır. Yukarıda belirtilen nedenlerle, bu uygulama (ekim ile birlikte azotun tamamı) kalibrasyon denklemi oluşturma 
amacı ile kullanılmakta olup hiçbir koşul altında çiftçiye tavsiye edilecek bir yöntem olarak düşünülmemiştir.

\subsection{Optik sensör ile bitki indekslerinin ölçülmesi}

Optik sensör ölçüm cihazları (GreenSeeker, Ntech Handheld505) ile normalize edilmiş vejetasyon indeks farkı (NDVI) ölçümü yapılmıştır (Şekil 1). Sistem, spektral yansıma prensibine göre çalışmakta olup, bu değerleri değişik dalga boylarındaki yansımalar üzerinden hesaplamaktadır (Peňuelas ve ark., 1993). Optik sensör okumaları bitki örtüsünden $80 \mathrm{~cm}$ mesafeden ölçülmüştür. Cihazın ölçüm işleminde kullandığı Eşitlik,1'de gösterilmiştir.

$$
\begin{aligned}
\mathrm{NDVI}= & \left(\mathrm{R}_{\mathrm{NIR}}-\mathrm{R}_{\mathrm{RED}}\right) /\left(\mathrm{R}_{\mathrm{NIR}}+\mathrm{R}_{\mathrm{RED}}\right) \\
& \mathrm{NDVI}=\left(\mathrm{R}_{900}-\mathrm{R}_{680}\right) /\left(\mathrm{R}_{900}+\mathrm{R}_{680}\right)
\end{aligned}
$$

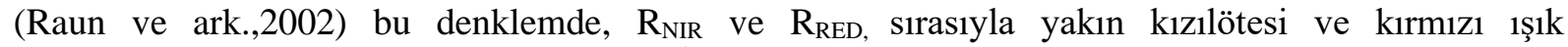
bölgelerindeki yansımaları göstermektedir. İki değer arasındaki farkın, iki değerin toplamına bölümü ise sensör tarafindan hesaplanıp NDVI olarak verilmektedir.

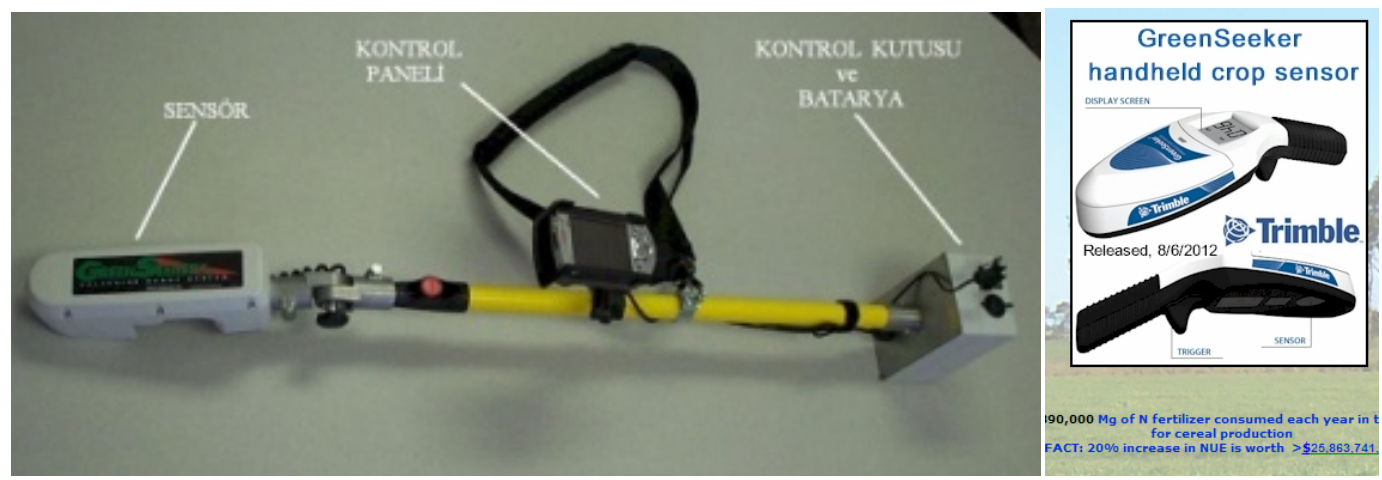

Şekil 1. NTech, GreenSeeker Model505, spektrometre ve küçük el tipi optik sensör.

4 dönemde indeks değerlerinden hesaplanan vejetasyon indeksine dayalı karşılık indeksi değerlerinin, hasatta verim açısından elde olunan gerçek karşılık indeksleriyle arasında korelasyon çalışması yapılmış ve okuma tarihleri için hesaplanan INSEY değerleriyle hasatta elde olunan gerçek verim değerleri arasındaki ilişkiden regresyon analizi sonucu kalibrasyon denklemleri hesaplanmıştır. Mevsim içi yansımaları kullanılarak, okuma anında azotça zengin şeridin NDVI değeri kontrol parsellerinin NDVI değerine bölünerek elde olunan değer de NDVI karş1lık indeksi (RI $\mathrm{NDVI}_{\mathrm{NDI}}$ ) olarak tanımlanmıştır ve bu iki indeks değeri arasında yüksek düzeyde korelasyon bulunduğu belirtilmektedir (Mullen ve ark.,2003). Buna göre, en yüksek dozda gübrelenen parsellerin verim değeri, diğer parsellerin verim değerlerine bölünerek elde olunan RI değerleri kalibrasyon denklemlerinin çiftçi tarlalarındaki uygulamalarında kullanılmıştır:

$$
\mathrm{RI}_{\text {Verim }}=\text { Verim }_{\text {(uygulama) }} / \text { Verim }_{\text {(kontrol) }}
$$

Okumaların yapıldığı Zadoks skalasına göre tarif edilen gelişme dönemlerinin seçiminde, bu konuda en yaygın araştırmaları yapmış ve yapmakta olan, Oklahoma Üniversitesi uygulamaları ve tavsiyeleri göz önünde bulundurulmuştur (Raun ve ark.,2002). Bu dönemlerde yapılan NDVI okumalarında elde olunan NDVI değerleri, ekimden itibaren geçen ve buğdayın gelişebileceği bir baz değerinin $\left(+4.4^{\circ} \mathrm{C}\right)$ üzerindeki gün sayısına bölünerek INSEY değerleri bulunmuştur (Raun ve ark.,2002). 
Çizelge 1. Enstitüde ölçülen yağış miktarları (2016-2019)

\begin{tabular}{|c|c|c|c|c|c|c|c|c|c|c|c|c|c|}
\hline YIL & 浔 & 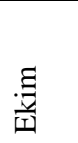 & 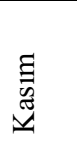 & $\begin{array}{l}\frac{y}{3} \\
\frac{\pi}{\pi}\end{array}$ & 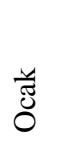 & $\begin{array}{l}\overrightarrow{\tilde{\Xi}} \\
\vec{\Xi} \\
\ddot{n}\end{array}$ & 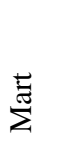 & 胥 & 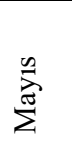 & $\begin{array}{l}\text { : } \\
\text { : } \\
\text { T్木 }\end{array}$ & 冡 & 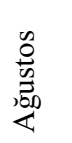 & $\begin{array}{c}\text { Toplam } \\
\text { (mm) }\end{array}$ \\
\hline Uzun y1l & 14.4 & 27.0 & 29.2 & 45.1 & 38.7 & 32.5 & 33.4 & 35.0 & 44.8 & 30.6 & 14.0 & 7.8 & 352.4 \\
\hline 2016-17 & 29.0 & 7.3 & 27.8 & 27.8 & 39.8 & 4.5 & 24.8 & 66.8 & 95.8 & 37.9 & 6.2 & 43.9 & 374 \\
\hline $2017-18$ & 0.5 & 48.4 & 28.6 & 41.8 & 29 & 41.6 & 41.1 & 9.5 & 92.5 & 73.8 & 60.1 & 14.6 & 482 \\
\hline 2018-19 & 1.0 & 10.3 & 20.3 & 45.9 & 60.2 & 50.1 & 13.4 & 26.7 & 42.2 & 45.7 & 33.5 & 2.4 & 352 \\
\hline
\end{tabular}

Çizelge 2. Deneme yerlerinden alınan toprakların kimyasal özellikleri $(0-30 \mathrm{~cm})$

\begin{tabular}{llccc}
\hline & & 2017 & 2018 & 2019 \\
\cline { 3 - 5 } \multicolumn{1}{c}{ Toprak özellikleri } & Birimi & ENSTİTÜ & ENSTİTÜ & ENSTİTÜ \\
\hline *Tekstür Sinıf & & $\mathrm{C}$ & $\mathrm{C}$ & $\mathrm{C}$ \\
$\mathrm{pH}(1: 2.5$.Toprak:Su) & & 7.52 & 7.36 & 7.6 \\
EC (Tuz) (1:5,Toprak:Su) & $(\mu \mathrm{S} / \mathrm{cm})$ & 140 & 130 & 168 \\
$\mathrm{CaCO}$ (Kireç) & $(\%)$ & 9.6 & 13.5 & 9.2 \\
Organik Madde & $(\%)$ & 1.1 & 1.31 & 2.08 \\
Fosfor (P) & $\mathrm{mg} / \mathrm{kg}$ & 32.1 & 8.39 & 20.6 \\
Potasyum (K) & $\mathrm{mg} / \mathrm{kg}$ & 666.7 & 365.4 & 1043 \\
Fenoldisülfonik Asit Metodu $\left(\mathrm{NO}_{3}\right)$ & $\mathrm{mg} / \mathrm{kg}$ & 3.3 & 2.29 & 4.7 \\
\hline
\end{tabular}

* C = Killi (Clay) 2017 YILI YKN1, 2018 YILI YKN2 VE 2019 YILI YKN3.

Çizelge 1'den de görüldüğü gibi 2017-18 yılında en yüksek yağış alınırken en düşük yağış ortalaması 2018-2019 yılında olmuştur. 2018-2019 yılında sonbahar yağışları düşük olması çıkışların gecikmesine neden olmuştur. Çizelge 2'de görüldüğü gibi deneme alanlarının toprak nitrat azotu düzeyleri düşüktür. Deneme yerleri seçilmeden önce örnek alınan tarlalardan bu özellikleriyle seçilmişlerdir. Deneme yeri topraklarının ince (killi) bünyeye ve düşük (\%1-2) düzeyde organik madde içeriğine sahip olduğu da görülmektedir. Ayrıca deneme yeri toprakları orta (\%5-15) ve fazla (\%15-25) kireçli, hafif alkalin reaksiyonlu, düşük tuzlu veya tuzsuzdur. Toprak analizleri örnekleri kurutulmadan araziden alındığı nemde Bremner (1965) tarafindan önerilen yöntemle $\mathrm{NO}_{3}$ azotu analizleri yapılmıştır. Bu örneklerde elde olunan analiz sonuçlarından, deneme kurulan alanlara ait veriler Çizelge 2'de verilmiştir. Kuru koşullarda metrekarede 500 tohum sıklığında ekilmiştir. Denemeler parsel mibzeri (Wintersteiger) ile sıra arası $20 \mathrm{~cm}$ ve 6 sıra olarak ekilmiştir. Parsel alanı ekimde $1.2 \times 7=8.4$ metrekaredir ve parsel alanının 1.2x5=6.0 metrekaresi parsel biçerdöveriyle (HegeWintersteiger) hasat edilmiştir.

Her ne kadar çalışmada çeşitlerin kendi kalibrasyon denklemleri kullanılmışsa da bölgede ekilen çeşit sayısının kalibrasyon çalışmasında kullanılan 4 çeşitten çok daha fazla olması ve her bir çeşit için ayrı kalibrasyon denemesi kurmanın zorluğu ve günümüzde sayıları giderek artan çeşit sayıları nedeni ile bu çalışmanın dışında yer alan çeşitlerin ekildiği tarlalarda yurtdışında olduğu gibi çeşitlerin ortalaması üzerinden elde olunan kalibrasyon denklemlerinin kullanılabileceği anlaşılmaktadır) (Raun ve ark., 2005). Çünkü verim potansiyelinden kaynaklanan, azot etkilerinin verime yansıma düzeyi arasındaki farklılıklar zaten bu yöntem tarafindan görülmekte ve hesaba katılmaktadır. Ayrıca mevsim içinde elde olunan okumalarla tahmin edilen biyolojik kütleye ilişkin değeri doğrudan kullanmaya oranla, bu biyolojik kütlenin ekimden itibaren birim zamandaki gelişmesini gösteren INSEY kavramının verim potansiyelini tahmin etmekte daha etkili olduğu bilinmektedir (Raun ve ark., 2002; Mullen ve ark., 2003).

$\mathrm{Bu}$ denemenin amacı, hasatta alınan verim karşılıklarının mevsim içi spektral yansıma okumaları ve bunlardan elde olunan vejetasyon indeksi değerleriyle hangi ölçüde uyumlu olduğunu belirlemek ve ilkbahar dönemi uygulanacak azot miktarının tavsiye edileceği denklemler elde etmektir. Demonstrasyon denemeleri: Azotlu gübre tavsiyesinde 2015-2018 yıllar1 arasında TAGEM destekli yürütülen TAGEM/TBAD/12/A12/P01/07-002' nolu ve TAGEM/TBAD/16/A12/P01/004' nolu Eskişehir koşullarında azotlu gübre kalibrasyonu isimli TAGEM proje sonuçlarından elde edilen kalibrasyon denklemleri kullanılarak azotlu gübre tavsiyeleri yapılmıştır. Sensör uygulamasına dayalı 
ve çiftçi uygulamasıyla karşılaştırmalı olarak azotça zengin şerit oluşturularak demonstrasyon çalışmaları yürütülmüştür.

Demonstrasyon çalışmasında 3 adet $3 * 7=21 \mathrm{~m}^{2}$ lik alana ekimle birlikte dekara $20 \mathrm{~kg}$ diamonyum fosfat gübre $(3.6 \mathrm{kgN} / \mathrm{da})$ uygulaması yapılmıştır. Zengin şerit olarak belirlenen ortadaki parsellere ilave olarak dekara $25 \mathrm{~kg} / \mathrm{da}$ üre $(11.4 \mathrm{kgN} / \mathrm{da})$ gübresi ilave edilerek geleneksel çiftçi uygulamasında olduğu gibi tüm parsellerin ekimi deneme mibzeri ile yapılmıştır. (Şekil 4). Ekim öncesinde $15 \mathrm{~kg} \mathrm{~N} / \mathrm{da}$ azotça zenginleştirilmiş $21 \mathrm{~m}^{2 \prime}$ lik azotça noksan olmayan bir zengin şerit oluşturulmuştur. Zadoks30 (sapa kalkma) döneminde zengin şerit ve çiftçi uygulama kısmından NDVI okuması yapılmıştır.

\subsection{Verilerin analizi}

Verilerin istatistiksel analizi JMP istatistik programı (JMP, SAS Institute, Cary, NC) aracılığıyla ile yapılmıştır. Bağımsız değişkeni (INSEY) ve Bağımlı değişken ise verim olan her çalışmada yapılması gerektiği gibi, regresyon analizlerine başvurulmuştur. Araştırmadan elde edilen verilerin varyans analizleri yapılarak istatistiksel önemde bulunan uygulamalara ait ortalama değerler Duncan çoklu karşılaştırma testi ile gruplanmıştır (Düzgüneş ve ark., 1987).

\section{Bulgular}

\subsection{Tane verimi}

Kuru koşullarda 4 buğday çeşitlerinin farklı azotlu gübre uygulamalarında, verim ve bitkinin farklı Zadoks 24, 30, 31 ve 32 gelişme dönemlerinde verdikleri NDVI değerlerine ait varyans analiz sonuçları (kareler ortalamaları) Çizelge 3'de verilmiştir. Denemede elde edilen verim sonuçları Çizelge 4'de verilmiştir. Çizelge 4. incelendiğinde, yıllar açısında en yüksek verim 699 kg/da ile 2018 yılında alınırken 2017 yılında $647 \mathrm{~kg} / \mathrm{da}$ ve 2019 yılında $278 \mathrm{~kg} / \mathrm{da}$ ile en düşük verim elde edilmiştir. 2019 yılında sonbahar yağışların geç gelmesi ve çıkışların gecikmesi verim düşüşüne neden olmuştur. Azotlu gübrelemeye karşıllk açısından tane verimleri değerlendirildiğinde 3 deneme ortalamasına göre en düşük verim $475 \mathrm{~kg} / \mathrm{da}$ ile kontrolde olurken artan azot dozları ile tane verimi istatistiki olarak önemli artış olmuş, en yüksek 584 kg/da ile 15 kg N/da seviyesinde gerçekleşmiştir.

Çizelge 3. Kuru koşullarda 4 buğday çeşidinin farklı azotlu gübre uygulamalarında, verim ve Zadoks 24, 30, 31 ve 32 dönemlerinde okunan NDVI değerlerine ilişkin kareler ortalamaları ve istatistiksel önemlilikleri

\begin{tabular}{|c|c|c|c|c|c|c|}
\hline \multicolumn{7}{|c|}{ Verim Kareler ortalamas1 } \\
\hline Varyansyon kaynağı & \multicolumn{2}{|c|}{ SD } & \multicolumn{2}{|l|}{ YKN1 } & YKN2 & YKN3 \\
\hline Çeşit (Ç) & \multicolumn{2}{|c|}{3} & $294819 * *$ & \multicolumn{2}{|c|}{$145302 * *$} & $248903 * *$ \\
\hline Azot (N) & \multicolumn{2}{|c|}{5} & 93988* & \multicolumn{2}{|c|}{$83474 * *$} & $330889 * *$ \\
\hline $\mathrm{C}^{*} \mathrm{~N}$ & \multicolumn{2}{|c|}{15} & 183554 & \multicolumn{2}{|c|}{$148097 * *$} & $73511^{*}$ \\
\hline Hata & \multicolumn{2}{|c|}{66} & 509840 & \multicolumn{2}{|c|}{228382} & 168709 \\
\hline \multirow[t]{2}{*}{ DK (\%) } & & & 4.5 & \multicolumn{2}{|c|}{6.9} & 13.5 \\
\hline & \multicolumn{6}{|c|}{ Kareler ortalaması } \\
\hline Varyansyon kaynağ1 & $\mathrm{SD}$ & Verim & NDVI ZD24 & NDVI ZD30 & NDVI ZD31 & NDVI ZD32 \\
\hline YIL (Y) & 2 & $5041513 * *$ & $0.997365^{* *}$ & $4.371476^{* *}$ & $0.632711^{* *}$ & $0.291292 *$ \\
\hline Çeşit (Ç) & 3 & $216883 * *$ & 0.005744 & $0.057043^{* *}$ & $0.021462 * *$ & 0.006799* \\
\hline Azot $(\mathrm{N})$ & 5 & $77926 * *$ & $0.140872 * *$ & $0.096366^{* *}$ & $0.105522 * *$ & $0.080936 * *$ \\
\hline $\mathrm{Y}^{*} \mathrm{C}$ & 6 & 6397 & $0.012808 * *$ & $0.032837^{* *}$ & $0.009471 * *$ & 0.004301 \\
\hline $\mathrm{Y}^{*} \mathrm{~N}$ & 10 & $11872 * *$ & $0.066203 * *$ & $0.038928 * *$ & $0.048391 * *$ & $0.031257 * *$ \\
\hline $\mathrm{C}^{*} \mathrm{~N}$ & 15 & $15147 * *$ & $0.006765 * *$ & 0.003671 & 0.002757 & 0.002527 \\
\hline $\mathrm{Y} * \mathrm{C}^{*} * \mathrm{~N}$ & 30 & 177952 & 0.001772 & 0.002391 & 0.002940 & $0.003615^{*}$ \\
\hline Hata & 199 & 906931 & 0.002434 & 0.002219 & 0.001983 & 0.002147 \\
\hline DK (\%) & & 12.5 & 8.4 & 7.7 & 6.3 & 6.2 \\
\hline
\end{tabular}

** İstatistiksel olarak \%1 düzeyinde önemlidir.* İstatistiksel olarak \%5 düzeyinde önemlidir. 
Çizelge 4. Kuru koşullarda azotlu gübre dozlarının yıllara ve buğday çeşitlerine göre tane verimlerine etkisi



Aynı harfle gösterilen ortalamalar birbirinden farksızdır.

Üç y1llık ortalamaya göre genotiplerden Nacibey (611 kg/da) en yüksek verimi vermiştir, onu sırasıyla Hat30 (559 kg/da), Mesut (500 kg/da) ve Reis (495 kg/da) çeşitleri izlemiştir (Çizelge 4).

Denemelerin verim ortalaması üzerinden çeşitlerin karşılaştırıldığ Çizelge 4 incelendiğinde ise, çeşitlerin azota verdikleri karşılık arasında farklılıklar olduğu ve bunun doğrudan doğruya çeşitlerin verim düzeyleriyle alakalı olduğu görülmektedir. Nacibey RI verim yönünden en yüksek karş1lık verirken, en düşük RI verim Mesut çeşidinde olduğu görülmektedir (Şekil 2). 


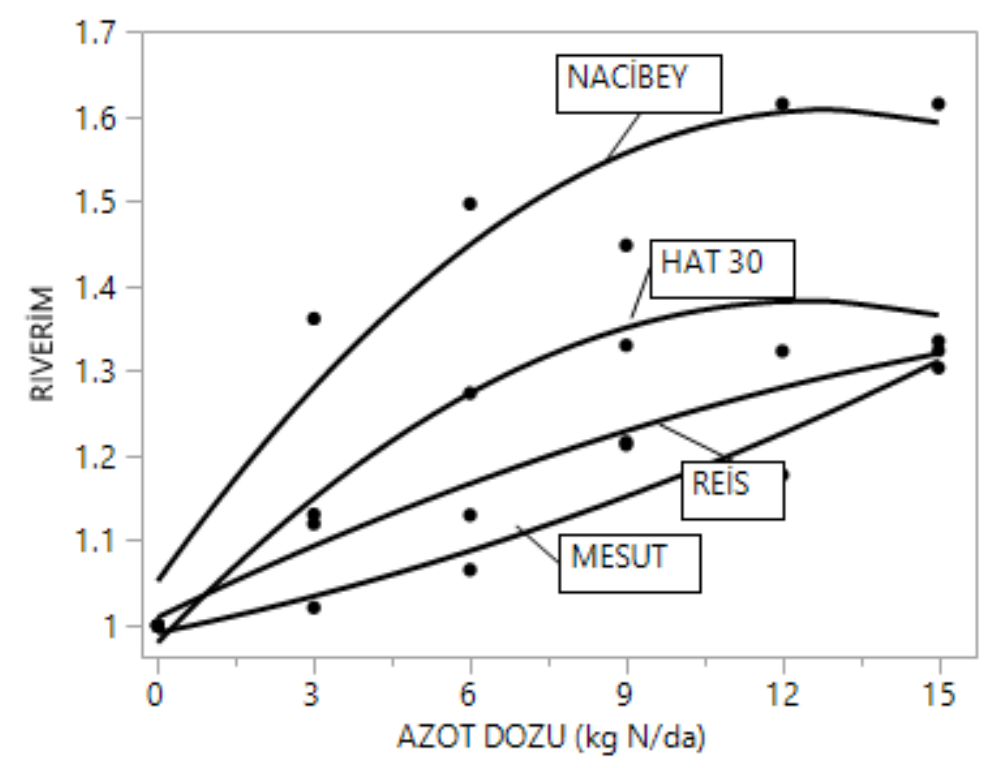

Şekil 2.Kuru koşullarda azotlu gübre dozlarının RI verim değerleri üzerine etkisi (3 yıl, 4 Genotip) RIVERIM.

\subsection{NDVI değerlendirmeleri}

Zadoks24, Zadoks30, Zadoks31 ve Zadoks32 elde olunan NDVI değerleri Çizelge 5'de verilmiştir. Çizelge 5'e bakıldığında 3 yıl ortalamaları değerlendirildiğinde dikkati ilk çeken, NDVI okuma dönemleri arasındaki gelişme farklılığının NDVI değerlerine yansıması olmaktadır. En düşük NDVI değerleri sırasıyla 0.584 NDVI değeri Zadoks24, onu sırasıyla 0.608 NDVI Zadoks30 dönemi, 0.711 NDVI değeri Zadoks31 döneminde ve en yüksek Zadoks32 dönemindeki okumalarda ise 0.750 NDVI değeridir. Genotipler değerlendirildiğinde en yüksek Mesut (0.684 NDVI), onu sirasıyla Reis (0.664 NDVI) takip etmiş, Nacibey (0.654 NDVI) ve en düşük NDVI değerini Hat30 (0.652 NDVI) genotipinden olduğu görülmüştür (Çizelge 5). Sonuçta, 3 denemede ve 4 farklı gelişme döneminde artan azot dozu ile birlikte NDVI değerlerinde artış olduğu Çizelge 5'de görülmektedir. ABD' de yapılan bir araştırma sonucunda da, $0.25^{\prime}$ in altındaki NDVI değerlerinin toprak yüzeyinin tam olarak kapanmamış olduğu anlamına geldiği, 0.25 ile 0.57 arasında azot ilavesinin yarar sağlayacağı, 0.73 değerinin ise ilave azottan yarar sağlanabilecek son düzey olduğu rapor edilmiştir (Raun ve ark., 2005).

Çizelge 5. Hat 30, Mesut, Nacibey ve Reis buğday çeşitlerinin farklı azotlu gübre uygulamalarında, Zadoks 24,30,31 ve 32 dönemlerinde verdikleri NDVI değerleri (3 yıllık ortalamalar)

\begin{tabular}{|c|c|c|c|c|c|}
\hline ZADOKS Dönemler & НАТЗ0 & MESUT & NACIBEY & REIS & Ort. \\
\hline NDVI ZD24 & $0.577 \mathrm{~b}$ & $0.588 \mathrm{ab}$ & $0.577 \mathrm{~b}$ & $0.595 \mathrm{a}$ & 0.584 \\
\hline NDVI ZD30 & 0.582 c & $0.647 \mathrm{a}$ & $0.592 \mathrm{c}$ & $0.610 \mathrm{~b}$ & 0.608 \\
\hline NDVI ZD31 & $0.699 \mathrm{~b}$ & $0.736 \mathrm{a}$ & $0.701 \mathrm{~b}$ & $0.709 \mathrm{~b}$ & 0.711 \\
\hline NDVI ZD32 & $0.748 \mathrm{~b}$ & $0.764 \mathrm{a}$ & $0.745 \mathrm{~b}$ & $0.742 \mathrm{~b}$ & 0.750 \\
\hline ORTALAMA & 0.652 & 0.684 & 0.654 & 0.664 & \\
\hline Azot Dozu (kgN/da) & NDVI ZD24 & NDVI ZD30 & NDVI ZD31 & NDVI ZD32 & Ort. \\
\hline 0 & $0.505 \mathrm{e}$ & $0.543 \mathrm{e}$ & $0.640 \mathrm{e}$ & $0.685 \mathrm{e}$ & 0.593 \\
\hline 3 & $0.549 \mathrm{~d}$ & $0.570 \mathrm{~d}$ & $0.675 \mathrm{~d}$ & $0.720 \mathrm{~d}$ & 0.628 \\
\hline 6 & $0.579 \mathrm{c}$ & $0.604 \mathrm{c}$ & $0.709 \mathrm{c}$ & $0.753 \mathrm{c}$ & 0.661 \\
\hline 9 & $0.611 b$ & $0.637 \mathrm{~b}$ & $0.734 \mathrm{~b}$ & $0.765 \mathrm{bc}$ & 0.687 \\
\hline 12 & $0.617 \mathrm{~b}$ & $0.636 \mathrm{~b}$ & $0.743 \mathrm{~b}$ & $0.778 \mathrm{~b}$ & 0.694 \\
\hline 15 & $0.644 \mathrm{a}$ & $0.661 \mathrm{a}$ & $0.766 \mathrm{a}$ & $0.797 \mathrm{a}$ & 0.717 \\
\hline ORTALAMA & 0.584 & 0.608 & 0.711 & 0.750 & 0.663 \\
\hline
\end{tabular}

Aynı harfle gösterilen ortalamalar birbirinden farksızdır. 


\subsection{Insey değerleri ve kalibrasyon denklemleri}

Azotlu gübrelemenin değişik Zadoks gelişme dönemlerinde buğday çeşitlerinin İNSEY değerlerine etkisi Çizelge 6' da verilmiştir.

Çizelge 6. Kuruda kalibrasyon denemesinde azotlu gübrelemenin değişik dönemlerde INSEY değerleri üzerine etkisi(3 yıl).

\begin{tabular}{cccccc}
\hline Azot Dozu (kg N/da) & HAT30 & MESUT & NACIBEY & REIS & Ortalama \\
\hline 0 & 0.00567 & 0.00609 & 0.00577 & 0.00620 & 0.00593 \\
3 & 0.00610 & 0.00640 & 0.00631 & 0.00626 & 0.00627 \\
6 & 0.00661 & 0.00671 & 0.00662 & 0.00642 & 0.00659 \\
9 & 0.00678 & 0.00726 & 0.00648 & 0.00685 & 0.00684 \\
12 & 0.00672 & 0.00709 & 0.00682 & 0.00697 & 0.00690 \\
15 & 0.00700 & 0.00738 & 0.00709 & 0.00705 & 0.00713 \\
\hline ORTALAMA & 0.00648 & 0.00682 & 0.00651 & 0.00663 & 0.00661 \\
\hline Azot Dozu (kg N/da) & INSEY ZD 24 & INSEY ZD 30 & INSEY ZD31 & INSEY ZD32 & Ortalama \\
\hline 0 & 0.00586 & 0.00567 & 0.00609 & 0.00611 & 0.00593 \\
3 & 0.00633 & 0.00591 & 0.00642 & 0.00641 & 0.00627 \\
9 & 0.00666 & 0.00627 & 0.00674 & 0.00670 & 0.00659 \\
12 & 0.00698 & 0.00661 & 0.00696 & 0.00681 & 0.00684 \\
15 & 0.00705 & 0.00659 & 0.00706 & 0.00691 & 0.00690 \\
\hline ORTALAMA & 0.00732 & 0.00685 & 0.00727 & 0.00708 & 0.00713 \\
\hline
\end{tabular}

Raun ve ark., (2001) yürüttükleri bir çalışmada mevsim içinde elde olunan okumalarla tahmin edilen biyolojik kütleye ilişkin değeri doğrudan kullanmaya oranla, bu biyolojik kütlenin ekimden itibaren birim zamandaki gelişmesini gösteren INSEY (In-Season Estimated Yield = Mevsim İçi Verim Tahmini) kavramının verim potansiyelini tahmin etmekte daha etkili olduğunu belirlemişlerdir. INSEY değerlerinin bağımsız, tane verimlerinin ise bağımlı değişken olarak kullanıldığı regresyon analizleri aracılığıyla kalibrasyon denklemleri hesaplanmıştır. NDVI değerlerinin her deneme için sabit bir gün sayısına bölünmesiyle bulunduğu için ayrıca istatistik analiz yapılmasına gerek kalmamış, bu nedenle her dönem için ayrı ayrı olmak üzere, INSEY değerleri 3 deneme ortalaması olarak Çizelge 6'da verilmiştir. 3 denemenin verim ortalamaları kullanılarak hesaplanan kalibrasyon denklemleri aşağıda verilmiştir.

HAT 30

ZADOKS24:VERIM(kg/da) $=13.8750+82156.21($ INSEY) ZADOKS30:VERIM $(\mathrm{kg} / \mathrm{da})=-228.90+131113.09$ (INSEY)

ZADOKS31:VERİM $(\mathrm{kg} / \mathrm{da})=-278.44+126276.4$ (INSEY)

ZADOKS32:VERİM(kg/da) =-524.46 +162763.1 (INSEY)

MESUT

ZADOKS24:VERIM(kg/da) $=290.99+30974.76($ INSEY)

ZADOKS30:VERIM $(\mathrm{kg} / \mathrm{da})=232.93+39183.77$ (INSEY)

ZADOKS 31:VERIM $(\mathrm{kg} / \mathrm{da})=179.44+45649.18($ INSEY $)$

ZADOKS 32:VERIM $(\mathrm{kg} / \mathrm{da})=62.09+64243.86($ INSEY $)$

NACIBEY

ZADOKS24:VERIM(kg/da) $=-518.73+171160.97$ (INSEY)

ZADOKS30:VERIM (kg/da) $=-399.65+165553.08($ INSEY)

ZADOKS31:VERİM $(\mathrm{kg} / \mathrm{da})=-537.24+173298.62($ INSEY)

ZADOKS32:VERIM(kg/da) $=-704.47+199388.09$ (INSEY) $\underline{\text { REIS }}$

ZADOKS24:VERIM(kg/da) $=240.51+36795.93$ (INSEY)

ZADOKS30:VERIM $(\mathrm{kg} / \mathrm{da})=259.39+36661.82($ INSEY $)$

ZADOKS31:VERIM $(\mathrm{kg} / \mathrm{da})=231.74+38610.63($ INSEY)

ZADOKS32:VERIM $(\mathrm{kg} / \mathrm{da})=-192.71+45261.38($ INSEY)

$$
\begin{aligned}
& \left(\mathrm{R}^{2}=0.78^{* *}, \mathrm{n}=6\right) \\
& \left(\mathrm{R}^{2}=0.91^{* *}, \mathrm{n}=6\right) \\
& \left(\mathrm{R}^{2}=0.90^{* *}, \mathrm{n}=6\right) \\
& \left(\mathrm{R}^{2}=0.91^{* *}, \mathrm{n}=6\right) \\
& \\
& \left(\mathrm{R}^{2}=0.87^{*}, \mathrm{n}=6\right) \\
& \left(\mathrm{R}^{2}=0.91^{* *}, \mathrm{n}=6\right) \\
& \left(\mathrm{R}^{2}=0.88^{* *}, \mathrm{n}=6\right) \\
& \left(\mathrm{R}^{2}=0.89^{* *}, \mathrm{n}=6\right) \\
& \\
& \left(\mathrm{R}^{2}=0.82^{*}, \mathrm{n}=6\right) \\
& \left(\mathrm{R}^{2}=0.87^{* *}, \mathrm{n}=6\right) \\
& \left(\mathrm{R}^{2}=0.89^{* *}, \mathrm{n}=6\right) \\
& \left(\mathrm{R}^{2}=0.95^{* *}, \mathrm{n}=6\right) \\
& \\
& \left(\mathrm{R}^{2}=0.80^{* *}, \mathrm{n}=6\right) \\
& \left(\mathrm{R}^{2}=0.78^{* *}, \mathrm{n}=6\right) \\
& \left(\mathrm{R}^{2}=0.79^{* *}, \mathrm{n}=6\right) \\
& \left(\mathrm{R}^{2}=0.85^{* *}, \mathrm{n}=6\right)
\end{aligned}
$$




\section{TÜM ÇEȘITLERIN ORTALAMASI ÜZERINDEN}

$$
\begin{aligned}
& \text { ZADOKS24:VERIM }(\mathrm{kg} / \mathrm{da})=-16.342+83250.64(\text { INSEY) } \\
& \text { ZADOKS30:VERIM }(\mathrm{kg} / \mathrm{da})=-77.0084+97906.5(\text { INSEY) } \\
& \text { ZADOKS31:VERIM }(\mathrm{kg} / \mathrm{da})=-150.44+102440.6 \text { (INSEY) } \\
& \text { ZADOKS32:VERIM }(\mathrm{kg} / \mathrm{da})=-303.41+126647.1 \text { (INSEY) } \\
& * \% 5, * * \% 1 \text { düzeyinde anlaml }
\end{aligned}
$$

$$
\begin{aligned}
& \left(\mathrm{R}^{2}=0.988^{* *}, \mathrm{n}=6\right. \\
& \left(\mathrm{R}^{2}=0.983^{* *}, \mathrm{n}=6\right. \\
& \left(\mathrm{R}^{2}=0.993^{* *}, \mathrm{n}=6\right. \\
& \left(\mathrm{R}^{2}=0.993^{* *}, \mathrm{n}=6\right.
\end{aligned}
$$

$\mathrm{Bu}$ denklemlerde ilk dikkati çeken durum, bütün çeşitler ve dönemler için INSEY değerleriyle verim arasında doğrusal ilişki bulunmuş olmasıdır. Tüm deneme ve çeşitler ortalamaları üzerinden elde edilen denklemlerde görüldügü gibi $(3,4,5 \mathrm{ve} 6)$, denemelerin ve çeşitlerin ortalaması üzerinden değerlendirildiğinde, tüm okuma dönemleri 0,01 düzeyinde önemli determinasyon katsayıları elde edilmiştir. Ancak, tüm denemelerin ortalaması üzerinden yapılan bu değerlendirmeye bakılırken, erken gelişmenin çok zayıf olduğu bazı tarlalarda Zadoks24 döneminde yapılan okumalar yanıltıcı sonuçlar verebilir. Sonuç olarak, sapa kalkmadan sonra, tarlaya traktörle girmenin zorluğu ve taşıdığı risk te düşünülerek Zadoks 3.0 (sapa kalkma başlangıcı) döneminin bu sistem için kuruda da en uygun okuma/gübre tavsiye dönemi olduğuna karar verilmiştir. Yurt dişında da, NDVI değerinin 0.25 ve altında olduğu durumlarda verim tahminlerinin yanıltıcı olabileceğine dair bilgiler vardır (Raun ve ark., 2005). Yurt dışındaki çalışmalarda ise genellikle üslü transformasyon denklemleri kullanılmaktadır (Ji ve ark., 2017;Teal ve ark., 2006). Bizim değerlerimizle yaptığımız çalışmada da üslü transformasyonlar denenmiş ancak doğrusal regresyona üstünlük sağlamamıştır. Gerek yurt dışında ve gerekse yurtiçinde yapılan çalışmalarda kuru şartlar için azotlu gübre kalibrasyon denklemlerin elde edildiği bildirilmiştir.(Cekic ve ark., 2008; Walsh ve ark., 2018) Yurt dış1 çalışmalarda elde olunan sonuçlarla aramızdaki bu farkın nedeni açık olmamakla birlikte, ABD'nin güneyinde yer alan Oklahoma ve Meksika'nın kuzeyinde bulunan Obregon'dan çok daha farklı bir iklim kuşağında bulunmamız buna neden olmuş olabilir. Sonuçta her bölge kendi kalibrasyon denklemleriyle çalışmak durumunda olduğuna göre, bizim için geçerli olan bu denklemler bölgemizdeki çiftçi tavsiyelerinde kullanılacaktır.

Diğer 3 dönem okumaları arasındaki determinasyon katsayısı farkları da önemli düzeyde olduğundan, çiftçi tarlalarındaki uygulamalar için Zadoks30 ve Zadoks31 dönemi en uygun bulunmuştur (Şekil 3). Sapa kalkma döneminde uygulanan azotun kışlık buğdayda gelişmeye en büyük etkiyi yaptığı belirtilmiş (Ali ve ark., 2020), aynı sonuca ulaşan (Melaj ve ark., 2003) bunu bu dönemin gelişme hızının maksimum olduğu dönem olmasına bağlamıştır. Ancak, erken gelişmenin ve kardeşlenmenin zayıf olduğu durumlarda, kardeşlenmeyi teşvik etmek için bir kısım azotun bu dönemden önce kullanılmasının yararlı olduğu da belirtilmektedir (Weisz ve ark., 2001).

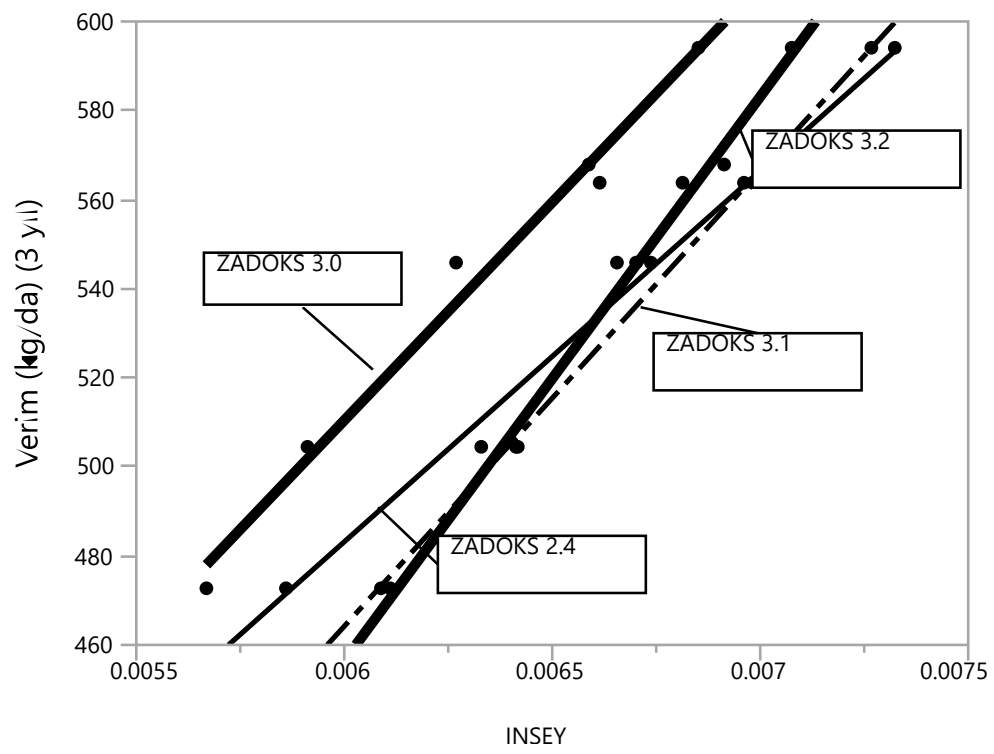

Şekil 3. Değişik okuma dönemlerinde hesaplanan INSEY değerleri ile verim ilişkisi. 
$\mathrm{Bu}$ durumda en doğrusu, erken ilkbahar döneminde zayıf kardeşlenmeyle girilen durumlarda bir miktar azotun erken dönemde verilmesi, ancak erken ilkbahar döneminde normal kardeşlenmeyle giren çeşitlerde sapa kalkma başlangıcında yapılacak optik sensör okumalarına dayalı tavsiyelerin göz önünde bulundurulması olmaktadır. Buğday sapa kalktıktan ve boğumlar çıktıktan sonra, tarlaya traktörle girmenin zorluğu ve taşıdığı risk düşünülerek, Zadoks30 döneminin bu sistem için en uygun okuma dönemi olduğuna karar verilmiştir. Burada dikkat edilmesi gereken en önemli husus, okuma döneminde bitkinin hangi gelişme safhasında olduğunun iyi belirlenmesi olmaktadır. Bunu daha iyi açıklayabilmek için, değişik dönemlerdeki INSEY verim ilişkisi Şekil 3' de grafik olarak gösterilmiştir. Şekil 3' den de görüldüğü gibi, aynı INSEY değerleri daha erken dönemde hesaplandığ1 taktirde daha yüksek verim tahmin etmektedir. Bitkilerin aynı gelişme durumunu daha erken elde etmesinin daha yüksek verim tahmini anlamına gelmesi doğal olduğundan, okumanın yapıldığı dönemin çok iyi belirlenmesi ve hangi dönemde okuma yapılmışsa o döneme ait kalibrasyon denkleminin kullanılması ön koşul olmaktadır. Bu çalışmada çeşitler arası farklılık bu sistem açısından önemli bulunmamıştır. Verim düzeyleri ise zaten genotipten bağımsız olarak sensör tarafından tahmin edildiği için, çeşitler arasındaki genotipik farklar, verim düzeyindeki farklara oranla önemsiz düzeyde kalmaktadır. Ancak çeşitler için söylenen bu durumun türler için de geçerli olacağını düşünmek yanlış olabilir. Nitekim Orta Anadolu ve Batı Geçit Bölgesi'nde yapılan bir çalışmada(Kalayci ve ark., 1996) makarnalık buğdayların ekmekliklerden daha düşük azot kullanma etkinliğine sahip olduğu, yani aynı verim düzeyine ancak daha fazla gübre kullanımıyla ulaşabildikleri görülmüştür. Yılmaz ve ark., (2020), başka bir çalışmada ise azot uygulamalarının azot kullanım etkinliğini arttırdığı, azotun fizyolojik, agronomik ve alım etkinliği üzerine etkisinin önemli olduğu bildirilmiştir.

\subsection{Demonstrasyon çalışmaları}

Çalışma kapsamında sensör uygulamasına dayalı ve çiftçi uygulamasıyla karşılaştırmalı olarak azotça zengin şerit oluşturularak demonstrasyon çalışmaları yürütülmüştür. İlkbahar Zadoks 3,0 (sapa kalkma) döneminde zengin şerit ve çiftçi uygulama kısmından NDVI okuması yapılmıştır.Şekil 4'de örnek bir azotlu gübre tavsiyesinin nasıl yapıldığı açıklanmıştır. Buna göre mavi renkli alanın doldurulması gerekmektedir. Tarlanın zengin şerit kısmından yapılan NDVI okuması (örneğin 0.635) olsun azot tavsiye tablosuna kayıt edilir. Yine çiftçi uygulaması kısmı ise çiftçinin normal geleneksel uygulama yaptığı alandan bir NDVI okuması yapılarak (örneğin 0.554) tabloya kayıt edilir. Ekimden okuma tarihine kadar geçen gün $\left(4.4{ }^{\circ} \mathrm{C}\right.$ üstündeki gün sayıs1) örneğin 99 gün olsun kayıt edilir. İlkbahar dönemi kullanılacak gübre çeşidi üre (\%46'lık) olarak excel tablosuna yazılır. Hesaplamaların sonucu yukarıda verilen denklemlerden daha ayrıntılı olarak incelenebilir. Excel dosyasında denkleme göre azotlu gübre tavsiyesi yapılır. Örneğimizde $5.3 \mathrm{~kg} / \mathrm{da}$ üre $(\% 46$ 'lık) uygulanması ile $465 \mathrm{~kg} / \mathrm{da}$ verim alınabileceği görülmektedir.

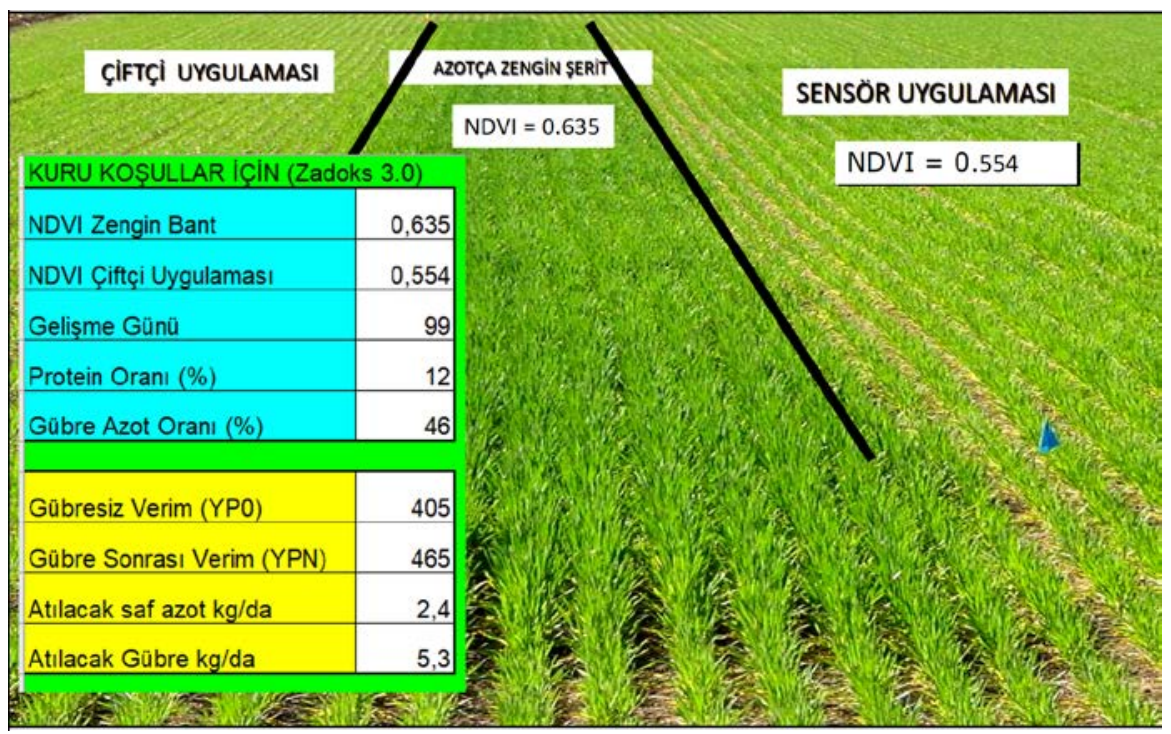

Şekil 4. Ekim öncesi çiftçi tarlasında zengin şerit oluşturulması. 
Tüm bu demonstrasyon çalışmasında okunan NDVI değerleriyle tavsiye yapılan azotlu gübre dozlarında alınan çiftçi uygulaması verimleri ve sensor uygulamasından alınan verimlere ve uygulanan azot değerlerine göre ekonomik analizler Çizelge 7'de verilmiştir. Çizelge 7'den de görülen ekonomik etkinlik hesaplanmasında, bu değerlendirmenin yapılmasında TMO'den elde olunan 2019 yılı resmi buğday alım fiyatları ile yine aynı dönemde piyasadaki \%46'lık üre fiyatlarının ortalamaları kullanılmıştır(Anonim,2019). Borsa prim uygulamaları bundan daha yüksek olmakla birlikte borsadan borsaya ve alım mevsimine göre değişiklik gösterdiğinden TMO rakamları esas alınmıştır. Buna göre, söz konusu dönemde $1 \mathrm{~kg}$ ürenin ortalama fiyatı $2.5 \mathrm{TL}$, buğday alım fiyat1 $1.33 \mathrm{TL}$ olarak alınmıştır.

Çizelge 7. Çiftçi uygulaması (CU) ve sensör uygulamasının (NDVI) ekonomik değerlendirilmesi (2 y1l, 4 genotip)

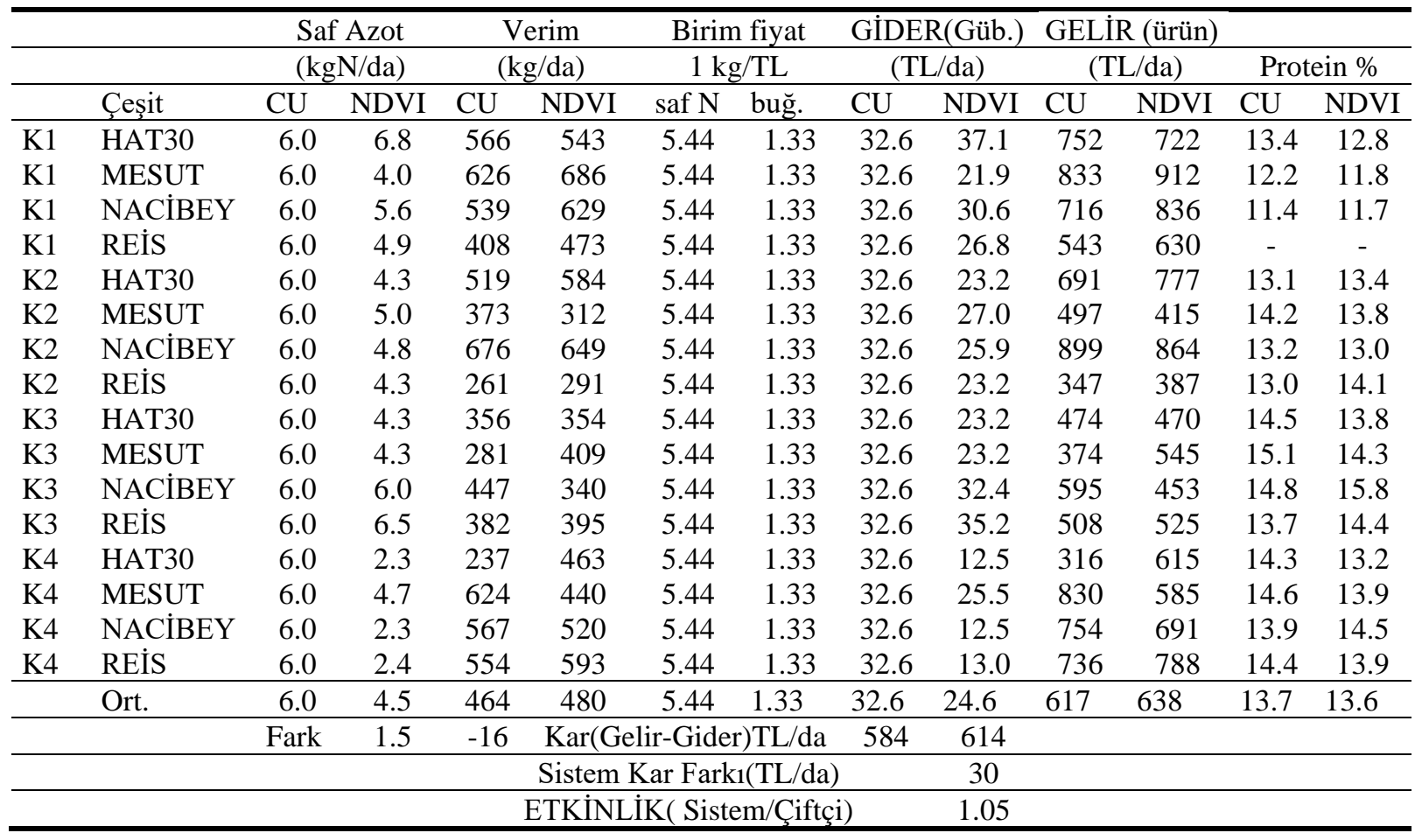

Demonstrasyonlar 4 ç4şit ile tekerrürsüz olarak yürütülmüştür. K:kuru demonstarasyon.

Daha öncede açıklandığı üzere çalışmanın yapıldığı yılın iklim koşullarının mevsim normallerinden çok farklı olmasına rağmen Çizelge 7'den de görüldüğü gibi sistem uygulaması (NDVI), çiftçi uygulamasına (CU) oranla ekonomik etkinlik yönünden \% $5^{\prime}$ lik bir avantaj sağlamıştır. $\mathrm{Bu}$ avantajın iklim koşullarının mevsim normallerine yakın olduğu yıllarda daha yüksek olması beklenmektedir. Burada sensör uygulaması çiftçi uygulamasına göre dekara $1,5 \mathrm{~kg}$ saf azot daha az kullanılarak aynı verim ve protein oranının elde edildiği görülmektedir. Burada sistemin ekonomik yönü daha avantajlı olduğu belirlenmiştir. Singh ve Mohamed (2020) tarlalarda oluşturulan zengin şeritlerde optik sensör kullanılarak azotlu gübre tavsiyesi yapılabileceği bildirilmiş̧ir. OrtizMonasterio ve Raun (2007) yürüttükleri çalışma sonuçlarına göre, çiftçi uygulamalarına kıyasla optik sensör uygulamalarıyla aynı verim düzeylerinde ortalama hektara $69 \mathrm{~kg}$ azot tasarruf sağlayabildiklerini bildirilmiştir.

\section{Tartışma ve Sonuç}

$\mathrm{Bu}$ çalışma kapsamında azotlu gübre tavsiyelerinde verim tahmini için kuru koşullarda kullanılan kalibrasyon denklemleri elde edilmiştir. Günümüzde sayıları iyice çoğalan çeşitlerin her biri için kalibrasyon çalışması yapmaya gerek olmadığını, Oklahoma ve Meksika'da olduğu gibi tüm çeşitlerin ortalaması üzerinden elde olunacak denklemlerin yeterli olduğunu görülmektedir. Yurt dışındaki çalışmalarda ise genellikle üslü transformasyon denklemleri kullanılmaktadır. Bizim 
değerlerimizle yaptığımız çalışmada da üslü transformasyonlar denenmiş ancak doğrusal regresyona üstünlük sağlamamıştır.

Bu çalışmada ikinci önemli bulgu ise yılın bitki gelişme durumuna göre Zadoks31 döneminde optik sensör okumalarına göre azotlu gübre tavsiyesi yapılabileceği belirlenmiştir. Bu durum tarlaya girilebilecek son dönem olduğu için bitki gelişimi çok iyi takip edilerek hızlı ve iyi gelişim olduğu yıllarda ve yüksek NDVI alınan yıllarda Zadoks30 dönemi tercih edilirken bitki gelişiminin zayıf olduğu yıllarda ise Zadoks31 dönemi tavsiye edilebilir. Bu konudaki çalışmalar devam etmektedir. Kuruda ZADOKS30:VERIM $(\mathrm{kg} / \mathrm{da})=-77.008+97906.5 * \operatorname{INSEY~}\left(\mathrm{R}^{2}=0.983^{* *}\right)$ uygun dönem olarak belirlenmiştir. Sonuç olarak; erken gelişmenin çok zayıf olduğu bazı tarlalarda Zadoks24 (4 kardeşli) döneminde yapılan okumalar yanıltıcı sonuçlar verebilir. Bu nedenle Zadoks30 (sapa kalkma) dönemi bu sistem için kuruda da en uygun okuma/gübre tavsiye dönemi olduğuna karar verilmiştir. Yapılan demonstrasyon çalışmalarında optik sensör (NDVI) uygulaması çiftçi uygulamasına (CU) göre ilkbahar döneminde dekara $1,5 \mathrm{~kg}$ saf azot daha az kullanılarak aynı verim ve protein oranı elde edildiği belirlenmiştir. Sonuçta sensör uygulamasının çiftçi uygulamasında göre ekonomik etkinliği $\% 5$ daha fazla olmuştur.

\section{Kaynakça}

Anonim. (2019). Toprak mahsülleri ofisi genel müdürlüğü http://www.tmo.gov.tr/Upload/Document /alim/201/2019alimfiyati.pdf. Erişim Tarihi:07.04.2020.

Ali, A.M., Ibrahim,S.M., \& Singh, B. (2020).Wheat grain yield and nitrogen uptake prediction sing at Leaf and GreenSeeker portable optical sensors at jointing growth stage. Information Processing in Agriculture, (In press.) doi.org/10.1016/j.inpa.2019.09.008.

Aparicio, N., Villegas, D., Araus, J.L., Casadesús, J., \&Royo, C. (2002).Relationship between growth traits and spectal vegetation indices in durum wheat. Crop Science, 42(5), 1547-1555.

Araus, JI., Bort,J., Ceccarelli, S, \& Grando, S. (1997)Relationship between leaf structure and carbon isotope discrimination in field grown barley. Plant Physiology and Biochemistry, 35, 533-541.

Bijay-Singh, Varinderpal-Singh, Yadvinder-Singh, Thind, H.S., Ajay-Kumar, Satinderpal-Singh, Choudhary, O.P., Gupta, R.K., \& Vashistha, M. (2013). Supplementing fertilizer nitrogen application to orrigated wheat at maximum tillering stage using chlorophyll meter and Optical Sensor.Agricultural Research, 2(1), 81-89.

Bremner, J.M. (1965). Nitrogen Ed.: C.A. Black. Ed: Method of soil analysis. part: ii. chemical and microbiological properties. Agronomy Series. No:9. Agronomy Inc. Madison. Wisconsin.USA

Cekiç, C., Savasli, E. Onder, O., Dayıglu, R., Gokmen, F., Dursun, N., \& S, Gezgin. (2008 Ekim). Bitkilerin azot kullanma etkinliğini artırmada mevsim içi azotlu gübre yönetiminin önem. i 4. Ulusal bitki besleme ve gübre kongresi, Konya.(s. 83).

Düzgüneş, O., Kesici, T., Kavuncu, O., \& F. Gürbüz. (1987). Araştırma ve deneme metodları (istatistik metodları 11.). Ankara Üniversitesi Ziraat Fakültesi yayın no:1021, 295s, Ankara.

Filella,I., Serrano, L., Serra, J., \& Penuelas, J. (1995). Evaluating wheat nitrogen status with canopy reflectance indices and discriminant analysis.Crop Science, 35(5),1400-1405.

Franzen, D., Kitchen, N., Holland, K., Schepers, J., \& Raun, W. (2016). Algorithms for in-season nutrient management in cereals. Agronomy Journal, 108(5), 1775-1781.

Jacob T., Bushong, Jeremiah L. Mullock,D. Brian, Arnall \& Raun, WR.,( 2018). Effect of nitrogen fertilizer source on corn (Zea mays L.) optical sensor response index values in a rain-fed environment. Journal Of Plant Nutrition, 41, 1172-1183.

Jensen, A., Lorenzen, B., Østergaard, H.S., \& Hvelplund, E.K. (1990). Radiometric estimation of biomass and nitrogen content of barley grown at different nitrogen levelsf. International Journal of Remote Sensing, 11(10), 1809-1820.

Ji, R., Ju, M., Wang, Y., Hu, C., Zhang, H., \& Shi, W. (2017).In-season yield prediction of cabbage with a hand-held active canopy sensor. Sensors (Switzerland), 17(10), 1-14.

JMP. (2014). Scintilla-Copyright (C) 1998-2014 by Neil Hodgson;neilh@scintilla.org SAS Institute. JMP 13.0 Users Guide. Carry, NC: Release SAS Institute Inc

Kalaycı, M., Kaya, F., Aydın, M., Özbek, V., \& Atlı, A. (1996).Batı geçit bölgesi koşullarında buğdayın verim ve dane protein kapsami üzerine azotun Etkisi. Turkish Journal of Agriculture and Forestry, (20), 49-59. 
Melaj, M.A., Echeverría, H.E., López,S.C., Studdert, G., Andrade, F., \& Bárbaro, N.O. (2003). Timing of nitrogen fertilization in wheat under conventional and no-tillage system. Agronomy Journal, 95(6), 1525-1531.

Mullen, R.W., Freeman, K.W., Raun, W.R., Johnson, G.V., Stone, M.L., \& Solie, J.B. (2003). Identifying an in-season response index and the potential to increase wheat yield with nitrogen. Agronomy Journal, 95(2), 347-351.

Odabas, M , Bajwa, S , Lee, C , Maraş, E . (2015). The prediction of saint john's wort leaves' chlorophyll concentration index using image processing with artificial neural network. Yüzüncü Y1l Üniversitesi Tarım Bilimleri Dergisi, 25 (3), 285-292. doi: 10.29133/ yyutbd.236409

Ortiz-Monasterio, J.I., \& Raun, W.R., 2007. Reduced nitrogen for improved farm income for irrigated spring wheat in the Yaqui Valley, Mexico, using sensor based nitrogen management. Journal Agricultural Science, (145), 215-222.

Peñuelas, J., Gamon, J .A., Griffin, K.L., \& Field, C.B.(1993). Assessing community type, plant biomass, pigment composition, and photosynthetic efficiency of aquatic vegetation from spectral reflectance. Remote Sensing of Environment, 46(2), 110-118.

Raun, W.R., Solie, J.B., Johnson, G.V., Stone, M.L., Lukina, E.V., Thomason, W.E., \& Schepers, J.S. (2001). In-season prediction of potential grain yield in winter wheat using canopy reflectance. Agronomy Journal, 93(1), 131-138.

Raun, W.R., Solie, J.B., Stone, M.L., Martin, K.L., Freeman, K.W., Mullen, R.W., Zhang, H., Schepers, J.S., \& Johnson, G.V. (2005).Optical sensor-based algorithm for crop nitrogen fertilization. Communications in Soil Science and Plant Analysis, 36(19-20), 2759-2781.

Raun, William R, Solie, J.B., Johnson, G.V, Stone, M.L., Mullen, R.W., Freeman, K.W., Thomason, W.E., \& Lukina, E.V. (2002). Improving nitrogen use efficiency in cereal grain production with optical sensing and variable rate application. Agronomy Journal,94, 815-820.

Savaşl1, E., Önder, Ö., Çekiç, C., Kalaycı HM., Dayığlu, R., Karaduman, K., Gökmen, F., Dursun, N., \& Gezgin, S. (2018). Sulu şartlarda ekmeklik buğdayda başaklanma döneminde yaprak solüsyon uygulamasının tane protein kapsamı üzerine etkisi. Türk Tarım-Gıda Bilim ve Teknoloji Dergisi, 6(1), 84-90.

Singh, Bijay \& Mohamed, Ali. (2020). Using hand-held chlorophyll meters and canopy reflectance sensors for fertilizer nitrogen management in cereals in small farms in developing countries. Sensors. 20.10.3390/s20041127.

Stone, M.L., Solie, J.B., Raun, W.R., Whitney, R.W., Taylor, S.L., \& Ringer, J.D. (1996). Use of spectral radiance for correcting in-season fertilizer nitrogen deficiencies in winter wheat. Transactions of the American Society of Agricultural Engineers, 39(5), 1623-1631.

Teal, R.K., Tubana, B., Girma, K., Freeman, K.W., Arnall, D.B., Walsh, O., \& Raun, W.R. (2006). Inseason prediction of corn grain yield potential using normalized difference vegetation index. Agronomy Journal, 98(6), 1488-1494.

Weisz,R., Crozier, C.R., \& Heiniger, R.W. (2001).Optimizing nitrogen application timing in no-till soft red winter wheat. Agronomy Journal, 93(2),435-442.

Westfall, D.G., Havlin, J.L., Hergert, G.W., \& Raun, W.R. (1996).Nitrogen management in dryland cropping systems. Journal of Production Agriculture, 9(2), 192-199.

Walsh, O., S., Shafian, S., \&Christiaens, R.J. (2018).Evaluation of Sensor-Based Nitrogen Rates and Sources in Wheat. International Journal of Agronomy.

Yilmaz F, Hamurcu M, Gezgin S. (2020) Determination of nitrogen use efficiencies of some bread wheat grown in the central anatolia region. Yüzüncü Yıl Üniversitesi Tarım Bilimleri Dergisi, 30(4): 689-695.

Zadoks, J.C., Chang T.T., \& Konzak, C.F. (1974). A decimal code for the growth stages of cereals. Weed Research, 14, 415. 